\title{
LA ENUNCIACIÓN NARRATIVA: EL NARRADOR Y LA VOZ DUAL
}

\author{
Luis Beltrán Almería \\ Universidad de Zaragoza
}

Fl giro pragmático que ha conocido la lingüística en los últimos tiempos ha difundido categorías que poca o ninguna importancia habían tenido anteriormente. Entre todas ellas nos interesan ahora dos: el sujeto de la enunciación y el sujeto de conciencia, por su trascendencia en todos los dominios, en especial en el análisis del discurso literario. A menudo son confundidas en una sola categoría por numerosos lingüistas. Sin embargo, resulta imprescindible su distinción y evaluación para no comprometer el futuro del giro pragmático.

El cultivo y clarificación de estas categorías es una de las más nítidas pruebas de la profundidad alcanzada en el giro pragmático. Escuelas de pragmática como la de Ginebra prescinden casi por completo de estas categorías, con lo que ponen de manifiesto su voluntad de mantener la pragmática como un dominio anexo de la semántica y, por consiguiente, la debilidad de su idea de discurso ${ }^{\text {I. }}$

La teoría del lenguaje literario no puede permanecer insensible a los avances del giro pragmático. Conceptos fundamentales como los de narrador, omnisciencia y problemas como los de la voz dual han de ser resituados más allá de la leve acomodación operada hasta el momento para encontrar sitio a las categorías pragmáticas.

1.- Berrendonner (1982), pragmático ginebrino, presenta una teoría de la enunciación que no se interesa por los problemas del sujeto. Ducrot (1980) y (1984) se limita a llamar la atención de la diferencia entre locutor y enunciador. 


\section{LUIS BELTRÁN ALMERÍA}

\section{El sujeto enunciador}

En general, debemos hoy la difusión de la categoría sujeto de la enunciación a la influencia de É. Benveniste y las escuelas que de él derivan. Revisaremos el alcance y el sentido de esta categoría en Benveniste y algunos de sus continuadores (Greimas, Ricoeur y Genette). También atenderemos a otra corriente que, aunque minoritaria, no ha dejado de tener una gran importancia en los debates lingüísticos de las últimas décadas: la corriente representada por Käte Hamburger — con su Die Logik der Dichtung -, proseguida después, por Ann Banfield, en un marco teórico generativista. Entre estas dos grandes líneas: la estructural y la lógica, trataremos de apuntar elementos para una concepción dialógica de la enunciación.

\section{El sujeto de la enunciación en Hamburger}

Hamburger (1957) aborda la enunciación con una perspectiva muy influenciada por su formación filosófica y, de inmediato, se apoya en criterios lógicos para definir el sujeto de la enunciación y los diferentes conceptos enunciativos. Su concepción de la teoría del lenguaje es la de un puente entre la gramática y la lógica:

Es handelt sich um die Lücke, die in Hinsicht auf das Problem der Aussage zwischen Logik und Grammatik besteht und nun freilich erst von einer dritten Disziplin, der Sprachtheorie, ausgefüllt werden kann (Hamburger 1957: 35).

Así, mientras la gramática - teoría de la comunicación- ve sólo el sujeto de la comunicación - el YO emisor, opuesto al TÚ receptor-, la teoría del lenguaje - teoría de la enunciación-, que domina la estructura oculta de la lengua, opone el sujeto de la enunciación al objeto:

D. h. es ist die Aussage, die als Subjekt-Objekt Struktur der Sprache sich darstellt (Ibid. 37).

y más abajo aclara:

Dabei ist das Aussageobjekt der Aussageinhalt in welcher Satzmodalität die Aussage auch erscheint (Ibid.).

Si la gramática concibe la lengua como un conjunto de palabras, susceptible de ser analizado, y la lógica la concibe como un conjunto de proposiciones, igualmente analizables, con la teoría del lenguaje podemos concebir la lengua como enunciación: una relación sujeto-objeto fijada de alguna forma y que mantiene algún tipo de relación con la cosa enunciada.

Para Hamburger, «todo enunciado es un enunciado de reálidad», pero la noción de realidad no se refiere al objeto del enunciado, sino al sujeto de la enunciación. Según esto, distingue tres grandes tipos de sistemas enunciativos (según su sujeto, pues según su objeto serían ilimitados):

- el sistema enunciativo histórico: con un sujeto individual y un tiempo concreto;

- el sistema enunciativo teórico: sin sujeto individual y con tendencia a la intemporalidad; $y$

- el sistema enunciativo pragmático: orientado hacia la acción y enclavado en el instante presente. 


\section{LA ENUNCIACIÓN NARRATIVA: EL NARRADOR Y LA VOZ DUAL}

Los géncros literarios han de ser revisados scgún la rclación sujeto-objeto que presentan. Y así tenemos dos grandes polos: los géneros ficticios o miméticos (Die fiktionale oder mimetische Gattung) y los géneros líricos (Die lyrische Gattung). En los géneros ficticios o miméticos (narrativa, teatro y cine) no hay un objeto: lo relatado no existe independientemente del hecho de su narración. La narración es, pues, una función productora del relato, lo mismo que el color para el pintor. El novelista no es un sujeto de la enunciación, puesto que no hay un objeto externo de la enunciación y no puede establecerse una relación sujeto-objeto. La desaparición de un sujeto de la enunciación, de un YOorigen real, es el elemento estructural esencial que define un mundo ficticio, cuyos indicios son el cambio semántico del pretérito, la transferencia de los adverbios deícticos hacia el campo nocional o simbólico, la posibilidad de utilizar verbos que refieren procesos interiores, etc.

Esta concepción logicista de la relación sujeto-objeto en los géneros literarios lleva a Hamburger a postular la exclusión de la lírica del dominio de la ficción, pues el YOlírico sí es un sujeto de la enunciación y la enunciación lírica pertenece al sistema enunciativo de la comunicación. Pero los problemas de Hamburger con la lírica desbordan nuestro tema.

En conclusión, podemos decir que la concepción hamburgeriana de la enunciación y de su sujeto es una concepción enteramente marcada por la herencia ideológica de G. Frege. Como Frege (1982), Hamburger niega cualquier valor veritativo a los enunciados literarios, carentes de referencia (Bedeutung en Frege) ${ }^{2}$. Pero, con este tipo de criterios, es muy difícil, por no decir imposible, constatar algo más que el valor veritativo de un enunciado. $\mathrm{Y}$ en los enunciados literarios eso significa constatar su ficcionalidad ${ }^{3}$. Los inconvenientes de un acercamiento tan rígido al discurso literario son, pues, superiores a sus prestaciones, por lo que resulta conveniente buscar una concepción de la teoría de la enunciación en una vía distinta de la «lógica lingüística» de Hamburger.

\section{El sujeto de la enunciación en Benveniste}

Quizá la concepción de la enunciación y su sujeto que mayor influencia ha tenido en la lingüística reciente sea la de Benveniste (1974). En el artículo titulado «L'appareil formel de l'énonciation", Benveniste define lo que entiende por enunciación y sus componentes formales fundamentales. Para el lingüista francés, la lengua no es más que la posibilidad del lenguaje. La enunciación materializa la lengua en una instancia de discurso, que emana de un locutor. La enunciación es, pues, un proceso de apropiación de la lengua por un locutor:

Le locuteur s'approprie l'appareil formel de la langue et il énonce sa position de locuteur par des indices spécifiques, d'une part, et au moyen dc procédés accessoires, de l'autre (Benveniste 1974: 82).

\section{2.- Como dice Lázaro Carreter:}

«El empeño de Käte Hamburger consiste en definir la literatura («Dichtung») como categoría ontológica diversa de la realidad" (1987: 10).

3.- Esta posición es compartida por Derrida y la corriente deconstruccionista, que saca de ella conclusiones extremas y se opone frontalmente al estructuralismo - tanto al francés, como al funcionalismo de Tel-Aviv-. Los estructuralistas, basándose en el concepto de mímesis, gradúan là relación supuesta entre el enunciado literario y su "realidad». 


\section{LUIS BELTRÁN ALMERÍA}

En la medida cn que Benvenistc concibe la cnunciación como un acto individual de apropiación de la lengua, supone inmediatamente la aparición de un EGO, centro de la enunciación, que se apropia ese aparato formal y que implanta al otro frente a él, estableciendo una relación dialógica permanente en cada enunciado. Anteriormente Benveniste había escrito:

C'est dans et par le langage que l'homme se constitue comme sujet; parce que le langage seul fonde en réalité, dans sa réalité qui est celle de l'être, le concept d'rego» (Benveniste 1966: 259).

Continuamente Benveniste insiste en una doble afirmación: el sujeto de la enunciación se apropia de la lengua y se funda frente a un tú, el otro. Con esta doble idea parece resolver dos problemas: enlaza la lengua con la enunciación, esto es, el sistema con el discurso; y sitúa el carácter dialógico del discurso, mediante la oposición yo/tú. He aquí uno de los nudos, si no el principal, de la distinción benvenisteana entre semiótica y semántica.

Pero los problemas que genera son, como veremos más adelante, superiores a los que resuelve. Resulta significativo que no pocos continuadores de la obra de Benveniste se hayan fijado en la oposición discurso/narración como fundamento para una teoría de los planos de la enunciación, antes que en la teoría personal enunciativa (es el caso entre otros de J. Simonin). En Greimas, que parte de una concepción muy justa de la teoría de la enunciación benvenisteana, veremos nuevas categorías y, en general, una decantación en la red de oposiciones binarias superior a lo que el buen criterio benvenisteano hubiera deseado. El diff́cil equilibrio entre lengua y discurso que intenta mantener Benveniste aparece en sus continuadores como una dura condena al mecanicismo y al binarismo, a menudo estériles.

\section{Los sujetos de Greimas}

A. J. Greimas ha desarrollado la teoría enunciativa de Benveniste, trabajando sobre el discurso narrativo y tomando también elementos de Jakobson. A partir de la noción de sujeto, construye un modelo acrónico, al que subordina los aspectos temporales del relato, introduciendo las reglas de transformaciones apropiadas. Define Greimas la enunciación de la siguiente manera:

la enunciación habrá de concebirse como un componente autónomo de la teoría del lenguaje, como una instancia que prepara el paso de la competencia a la performance (lingüísticas), de las estructuras semióticas virtuales que deberá actualizar a las estructuras realizadas bajo forma de discurso (Greimas-Courtés 1979: 144, citado por la traducción española).

Continúa la línea benvenisteana de concebir la enunciación como mediación entre la langue saussureana y el habla, ahora discurso. Su contribución consiste en desarrollar la autonomía de la instancia enunciativa. Este desarrollo presenta una doble vertiente: la del proceso mismo - con los conceptos de embrague y desembrague (embrayage y débrayage) - y la del sujeto o sujetos —enunciador/enunciatario, destinador/destinatario, sujeto cognitivo/sujeto pragmático, etc.-. Su aportación categorial resulta enormemente extensa en comparación con las de Hamburger y Benveniste, pero adolece de la rigidez geométrica de lo concebido a priori. Descansa su metodología en tres relaciones actanciales 
que componen otras tantas oposiciones binarias: deseo (el sujeto desea a su objeto), comunicación (el destinador se comunica con su destinatario) y acción (el adyuvante actúa sobre su oponente).

Dada la extensión y complejidad de la teoría enunciativa de Greimas $-\mathrm{y}$ dado que, en lo esencial, sigue a Benveniste-, nos limitaremos a apuntar los aspectos más útiles para nuestra investigación, aun a riesgo de ofrecer un tratamiento injusto de este lingüista.

En primer lugar, nos interesa una advertencia que Greimas suele reiterar:

el sujeto de la enunciación, responsable de la producción del enunciado, permanece siempre implícito y presupuesto, nunca está manifestado en el discurso-enunciado (ningún «yo», encontrado en el discurso, puede ser considerado como sujeto de la enunciación propiamente dicha ni identificado con él: se trata tan sólo de un simulacro de la enunciación, es decir, de una enunciación enunciada (o referida) (Greimas-Courtés 1979: 113).

La enunciación enunciada es para Greimas «mero simulacro que imita, en el discurso, el hacer enunciativo" y debe considerarse «como una subclase de enunciados, que se ofrecen como el metalenguaje descriptivo (pero no científico) de la enunciación» (ibid. 146). Con estas objeciones Greimas apunta un problema derivado de su arquitectura teórica: el sujeto de la enunciación no es nunca un elemento del discurso. Entre el sujeto y el pronombre afirma la existencia de una mediación: el desembrague, cuyo valor expondremos a continuación. Pero además expresa la dificultad que siente, ante el discurso y sus manifestaciones rebeldes al encasillamiento binario, el teórico que trabaja exclusivamente con categorías binarias y estructuradas en torno a un inventario cerrado ${ }^{4}$.

En segundo lugar nos interesa revisar el doble concepto de embrague/desembrague. Fruto de la rígida distribución entre enunciador y destinador, por un lado, y sus representaciones actanciales, por otro, es el concepto de desembrague, categoría mecánica que Greimas relaciona con los shifters de Jakobson. Se trata de la operación por la que la instancia enunciadora proyecta fuera de ella - es decir, al discurso - «ciertos términos vinculados a su estructura de base, a fin de constituir así elementos fundadores del enunciado-discurso" (ibid. 113). Esto significa que la enunciación, en tanto que mediación entre lengua y discurso, aprovecha las categorías paradigmáticas de persona, espacio y tiempo para instalar el discurso explícito. A nuestro juicio, esta categoría evidencia dos limitaciones de la teoría de la enunciación de Greimas, que son la doble cara del mismo problema. Se ha visto obligado a generar unas categorías mecánicas por mantener su dependencia de la oposición saussureana langue y - ahora- discurso, en la línea de Benveniste, lo que supone la justificación de los mecanismos que hacen posible la enunciación como mediación entre la lengua y el discurso. Esta limitación proviene desde el punto de vista del proceso enunciativo. Desde el punto de vista del producto enunciativo -el enunciado-, evidencia la ignorancia del papel regulador del género del discurso, que provee al sujeto de todas las categorías paradigmáticas y sintagmáticas precisas, tomadas de la inmediatez del discurso ajeno. Dicho en un lenguaje menos críptico, un sujeto - por ej., un niño - produce un discurso que se materializa en enunciados concretos, orales o escritos, que emanan del papel que cumple en un determinado dominio de la

4.- Según Ricoeur (1984: 85, ed. esp.), la elección por Greimas de su perspectiva actancial tiene la ventaja — respecto a Propp u otros - de que la lista de actantes es considerablemente más corta que la de las funciones del relato, y sus interacciones se prestan de entrada a una representación paradigmática. 


\section{LUIS BELTRÁN ALMERÍA}

actividad humana - en el caso del niño, el escolar o el familiar-; los diferentes componentes de ese discurso los toma el sujeto del discurso ajeno - en nuestro ejemplo, el discurso de otros niños, de los padres, de los maestros, etc.-- a través de los géneros del discurso, que se le ofrecen como las diferentes instancias del discurso -en nuestro ejemplo, el ruego, la orden, la pregunta, el saludo, etc.- La enunciación no es, pues, mediación entre lengua y discurso, como opina la corriente benvenisteana, sino producción de discurso entre discursos genéricos.

El tercer, y último, aspecto que nos interesa de la teoría de la enunciación de Greimas es el sujeto cognitivo. Greimas encuentra en la dimensión cognitiva del discurso narrativo un paralelo superior a la dimensión pragmática, que toma a su cargo el sujeto mediante su saber. Llama sujeto cognitivo al sujeto que el enunciador instala en el discurso y le otorga un saber total o parcial, esto es, supone una versión de lo que para muchos es el narrador. El sujeto cognitivo puede aparecer en sincretismo con el sujeto pragmático (el héroe) o ser diferente, en cuyo caso aparece un observador - quedando implícito y no siendo reconocible sino gracias al análisis semántico, que revela su presencia en el discurso-, o puede quedar en sincretismo con otro actante (el YO-testigo). En nuestra opinión, el sujeto cognitivo es uno de los elementos más interesantes de la constelación de sujetos que nos propone la semiótica narrativa de Greimas,

\section{Otras propuestas}

Además de Hamburger, Benveniste y Greimas, otros teóricos se han ocupado del sujeto de la enunciación, pero sin concederle la misma importancia en sus sistemas categoriales.

Banfield (1982) prefiere hablar de SELF. Ella misma nos explica las razones y to que entiende por ello:

The term SELF is a substitution for «subject-of-consciousness» used in Banfield (1973). The principal reason for the change in terminology is that SELF abbreviates the longer term; there is no substantive difference between SELF and subject-ofconsciousness. (...) Lacan's term sujet de l'énonciation, as discussed in Milner (...), can be directly related to the concept of SELF used here (Banfield 1982: 293).

Como puede apreciarse, Banfield parece confundir sujeto de la enunciación y sujeto cognitivo. Sin embargo, Hamburger - que sirve de referencia a Banfield - no cree que sean lo mismo. Aunque la teórica alemana dice que ambos sujetos son practicamente idénticos, señala que la diferencia estriba en que la enunciación es una construcción lingüística $y$, por tanto, sujeta a formas y el conocimiento no, es sólo pensamiento y no puede estar fijado. Esta diferencia, por otro lado, en absoluto profundizada y deficientemente explicada por Hamburger, da lugar a la confusión de Banfield. La generativista norteamericana prescinde de la oposición enunciado-enunciación, tan cara a Hamburger, y mal puede hablar entonces de un sujeto enunciativo. Sin embargo, el desarrollo que hace de la primera y de la segunda persona, siguiendo las ideas benvenisteanas de la subjetividad en el sistema personal -los componentes SPEAKER/SELF de la primera y HEARER/ADDRESSEE de la segunda - muestra un SELF que es más sujeto de la enunciación que sujeto cognitivo. El escaso desarrollo de la noción banfieldiana de SELF parece indicar una clara confusión de contenidos.

Algo similar sucede en Tamir (1976). En este trabajo, que ha alcanzado en la última 


\section{LA ENUNCIACIÓN NARRATIVA: EL NARRADOR Y LA VOZ DUAL}

década entre los teóricos de la literatura una notoria autoridad, se mantiene la confusión banfieldiana. Tamir equipara las categorías verbales de Jakobson (1970) a las categorías personales de Benveniste; sigue con la consideración —explícita-del SELF de Banfield como sujeto enunciativo al estilo de Benveniste e, incluso, prosigue la argumentación banfieldiana de la imposibilidad de dos SELVES en un mismo enunciado -aunque admite voz dual en el discurso indirecto libre de la narrativa en tercera persona-. Si Banfield rehuye la denominación sujeto de la enunciación para su SELF, después de 'eér a Tamir la identificación entre ambas categorías ha culminado la confusión preexistente. Ambas teóricas siguen líneas distintas en lo que se refiere al narrador. Banfield continúa la línea de Hamburger. No existe el narrador, salvo en la narrativa en primera persona. Tamir evita una exclusión tan tajante y establece una gradación entre la narrativa personal, con un narrador evidente, y la narrativa impersonal, en la que el narrador no puede ser detectado. Ambos casos son polos ideales de una escala que admite diversos grados. Justifica Tamir su diferencia con Hamburger y Banfield en que su propuesta es más funcional que ontológica.

Por último, nos referiremos a la actitud de Genette y Ricoeur. Ambos postulan dos categorías voz y punto de vista o focalización, que responden respectivamente a las preguntas ¿quién habla? y ¿quién ve o percibe? Esta distinción parece sugerir la división entre sujeto de la enunciación y sujeto cognitivo - lo que sería totalmente justo-, pero esta interpretación no es posible porque Genette sigue la opinión de Todorov de que el récit no es una forma diferente de hablar. Genette piensa que en toda narración siempre hay o puede haber un YO - propone un ejemplo quijotesco: «en un lugar de la Mancha de cuyo nombre no quiero acordarme ....-. El sujeto de la enunciación para Genette - lo mismo que para Tamir y para Benveniste - es siempre YO, que además es el narrador - como en Kayser (1958), que siempre supone un narrador, aunque en este caso sea una figura ficticia, el «espíritu del relato»-, con lo que borra - Genette- toda frontera entre la narrativa en tercera o primera persona y de paso entre discurso literario y discurso común. Ricoeur (1986) ha desarrollado una teoría de la enunciación de corte benvenisteano. Ricoeur propone aspectos renovadores de interés. En primer lugar, considera el discurso como hecho y como significación («si tout discours est effectué comme événement, tout discours est compris comme signification». Ricoeur 1986: 105). Para desarrollar el aspecto significativo echa mano de la teoría del Speech-Act de Austin y Searle. El mayor interés de su concepción enunciativa radica en su planteamiento de la obra literaria como resultado de un trabajo que organiza el lenguaje - la obra de discurso-. La materialización de ese trabajo es el estilo, cuya noción acumula los caracteres de hecho y sentido. Sin embargo, no nos detendremos en la concepción enunciativa de Ricoeur porque su tratamiento del "sujeto del discurso» sólo es consecuencia de la individualización que el estilo opera sobre la obra artística - por este método el "sujeto del discurso" se trasforma en autorartista-. Por lo demás identifica con demasiada facilidad al sujeto con el locutor ${ }^{5}$.

5.- En su ensayo sobre el cronotopo, Bajtín (1975) explica la distancia existente entre el autor y el YO de la ficción, aun en el caso de la autobiografía más veraz. Identificar absolutamente el yoautor con el yo-narrador es tan imposible como elevarse uno mismo tirándose de los pelos; el cronotopo textual nunca puede corresponderse con el cronotopo real. Esta distinción, sin embargo, es útil para fundar el concepto de ficción, pero se trata de un criterio ontológico y, por tanto, incapaz de arrojar luz sobre el problema enunciativo. 


\section{LUIS BELTRÁN ALMERÍA}

\section{Sujeto y observador}

Tenemos, pues, dos líneas de teorización sobre el sujeto de la enunciación -Hamburger y Benveniste/Greimas - y otros que, o bien se han dedicado a seguir sendas abiertas - con no demasiada fortuna -, o bien han rehuido el problema, poco deseosos de enfrentarse a cuestiones linguíísticas. Más arriba ya hemos expresado nuestra objeción a la concepción lógico-positiva de la enunciación de Hamburger. Estas posiciones ontológicas sólo sirven para alcanzar resultados doctrinarios y arrojan poca luz sobre la naturaleza del lenguaje - que no es precisamente lógica, en el sentido que entienden esta palabra las diversas corrientes de la fílosofía del lenguaje actuales-. Benveniste, en cambio, se sitúa por completo en el dominio lingüístico. Sin embargo, se puede objetar a su concepción de la enunciación una concesión a las posiciones estructuralistas. En efecto, Benveniste define - acertadamente, a nuestro juicio - la enunciación como una apropiación del sujeto, pero discrepamos con él en el objeto de la apropiación. Fl sujeto enunciativo no se apropia de la lengua, como dice Benveniste, no se apropia de una gramática y de un diccionario, se apropia de enunciados vivos, se apropia de discurso ajeno. Esta es una de las grandes lecciones del círculo de Bajtín ${ }^{6}$. Categorías como gramática y vocabulario sólo existen como abstracciones útiles para los lingüistas, pero no tienen entidad real. Lo real es el discurso y sus enunciados.

Ahora podemos entender mejor la segunda parte de la definición benvenisteana del sujeto enunciativo. Este sujeto se funda frente al otro, frente a un tú, según Benveniste, que desciende demasiado rápidamente al plano de la lengua - al sistema personal - En este elemento de la definición resulta más clara la concepción de Hamburger, que opone el sujeto al objeto, entendido como el contenido de la enunciación (Aussageinhalt). Pero, expresado así, volvemos a tener una visión lógica. El contenido de la enunciación debe ser reemplazado por los enunciados vivos que rodean al sujeto, esto es, el discurso ajeno, para superar la orientación objetual hamburgeriana.

La definición benvenisteana resulta excesivamente ambigua. Es cierto que un sujeto se afirma frente a otro sujeto, pero, dicho así, se pierde de vista la relación del sujeto con el discurso: la relación de un sujeto con otro es a través del discurso del otro. La incomprensión de este fenómeno lleva a Benveniste a enfrentar los sujetos directamente y a ponerlos en contacto directo con la lengua - con lo que ésta adquiere status de ente-. Esta actitud conlleva errores de apreciación, incluso para la propia lengua. Por ejemplo, al sacar consecuencias sobre la subjetividad en el dominio del sistema personal, Benveniste pierde el espacio necesario para desarrollar una visión más profunda del sujeto enunciativo y esto le lleva a ignorar problemas como los del discurso indirecto libre o la voz dual.

Este sujeto, que enuncia apropiándose del discurso ajeno, adopta diferentes posiciones según el género del discurso que practique. Y, sin duda, el género en el que pone al descubierto de forma más clara sus virtualidades es el discurso narrativo, en cuyas realizaciones históricamente recientes presenta problemas con un alto grado de complejidad -en general, los que caen bajo el epígrafe de la voz dual-. ¿Por qué sucede esto en el discurso narrativo? Pueden formularse dos grandes hipótesis. La primera es que, al ser un discurso escrito, resulta un discurso más elaborado y fijado - literal一, sobre todo si

6.- El círculo de Bajtín desarrolló una teoría de la enunciación, basada en la ruptura con la lingüística saussureana y en la dialéctica personal que se establece entre los sujetos enunciadores. Véase Voloshinov (1929) El marxismo y la filosofía del lenguaje y Bajtín (1979) «Los géneros del discurso» en Estética de la creación verbal. 


\section{LA ENUNCIACIÓN NARRATIVA: EL NARRADOR Y LA VOZ DUAL}

tenemos en cuenta su función estética. La segunda es que, dentro de los discursos de ficción, es el que, en mayor medida, confronta un discurso ajeno personalizado - el discurso de los personajes - con el discurso del autor, lo que produce interacciones entre ambos discursos y pone de manifiesto vertientes que en otros géneros pasan frecuentemente desapercibidas. Desde un punto de vista histórico, el discurso narrativo es el discurso artístico-literario que se ha visto obligado a hacer un mayor esfuerzo de puesta en funcionamiento de unas leyes lingüísticas específicas y que lo definen entre los géneros artísticoliterarios. Así como la lírica, el teatro o, incluso, el cine pueden utilizar leyes de discurso provenientes del discurso oral con limitaciones, esto no es posible en el discurso narrativo, que presenta las leyes discursivas más distantes de la comunicación oral habitual, al tener que crear un espacio y un tiempo ficticios, en los que chocan el autor-narrador y sus figuras.

Entre los efectos que produce la posición especifica del sujeto de la enunciación en el discurso narrativo cabe señalar la disociación de su papel de enunciador de su función cognitiva. Por esto en lo sucesivo hablaremos de enunciador -o sujeto enunciativo- y sujeto cognitivo $-\mathrm{u}$ observador- para designar las dos realizaciones del sujeto de la enunciación en el discurso narrativo. El enunciador - o sujeto enunciativo- actúa sobre la elección y organización de elementos linguísticos; el sujeto cognitivo -o de concienciaactúa sobre el contenido temático del discurso.

La distinción entre sujeto de la enunciación y sujeto cognilivo liene varias argumentaciones posibles. Una es la evidencia de que hay frases narrativas que exigen la pregunta ¿quién habla? y frases que exigen la interrogación ¿quién ve? o ¿quién sabe? Unas frases expresan discurso, otras imágenes. A este primer nivel de justificación pertenecen las divisiones categoriales de Genette, Stanzel (1979) y Ricoeur (1984). Se trata de una línea de argumentación pragmática, que alcanza su fundamento en el hecho de que el género humano sólo dispone de dos tipos de actividades inteligentes básicas: el conocimiento y la expresión oral. Estas dos actividades básicas configuran el discurso que puede articular, son los límites del discurso humano. El discurso se configura por lo que puede ser conocido y puede ser expresado y en su configuración más compleja puede tender hacia el límite del conocimiento o hacia el límite de la expresión ${ }^{7}$. La segunda argumentación, complementaria con la anterior, tiene su origen en el doble componente del discurso interior. En efecto, el discurso interior es a la vez un producto acústico y un producto semántico. Cuando el discurso interior se oraliza su realización mental parece consistir en significados puros; el componente semántico es hegemónico. Sin embargo, cuando el discurso interior no se oraliza, suele resultar hegemónico el componente acústico —las imágenes acústicas--, generándose un pensamiento verbal. La descomposición del YO ha dado lugar a formas narrativas construidas sobre la base de estos componentes del discurso interior: el acústico produce el discurso verbal; el semántico, las imágenes narrativas. Esta distinción entre los dos componentes del discurso interior se debe a Vygotski (1934), a quien debemos la mejor concepción de este fenómeno ${ }^{8}$.

7.- La oscilación entre ambos límites es una constante de la historia literaria. La novela del siglo XX oscila entre dos grandes polos: la novela llamada social y la novela llamada deshumanizada. En la novela social domina una orientación hacia el polo del conocimiento: el autor-narrador adopta una posición de observador neutro, no se preocupa tanto de alcanzar exquisiteces compositivas como de apuntar datos y testimonios. En la novela deshumanizada la complejidad verbal es la tarea principal; la atención hacia la dimensión verbal del discurso del personaje es prioritaria, los juegos lingüísticos e idiomáticos florecen.

8.- La prueba de la existencia de ambos componentes la encuentra Vygotski en el discurso egocéntrico 


\section{LUIS BELTRÁN ALMERÍA}

\section{El narrador}

Resulta curiosa la unanimidad alcanzada entre los teóricos de la literatura de este siglo — desde Käte Friedmann, en 1910 - en torno al concepto de narrador. Se trata de un concepto imprescindible para la teoría literaria actual, a excepción de Hamburger y Banfield. Y lo curioso es que semejante imprescindibilidad se basa en una amplia gama de caracterizaciones difícilmente conciliables. Esta gama puede reducirse a tres posiciones básicas, que definiremos del siguiente modo:

1. El narrador es un espíritu, el espíritu del relato. Este espíritu puede ser generado por metamorfosis del autor - así parece que lo entiende Kayser (1958) - o puede tener otras génesis más oscuras. Así, un reciente manual de teoría literaria dice: «quien lee una novela no se constituye en sujeto de la enunciación; configura en su propia mente a alguien que le está hablando: este es precisamente el narrador, suya es la voz imaginaria que articulamos en nuestra mente» ${ }^{9}$.

2. El narrador es un YO que siempre es posible en cualquier relato. Es la posición de Genette (1972), de Greimas y de Ross (1970), que encuentra todos los enunciados de una novela como explícita o implícitamente performativos, pues se puede suponer un «digo que».

3. El narrador admite una amplia gama de representaciones que discurre entre dos polos opuestos: el grado pleno de la narración personal - la narración en primera persona-y el grado cero de la narración impersonal - la narración en tercera persona más objetivista-. Es la posición de Tamir (1976).

Las tres posiciones responden a diferentes concepciones de la obra literaria. Pero las tres responden a sendos principios compartidos y que podemos describir así:

1. La figura del narrador se concibe como una categoría abstracta - ya sea narrativa o linguística - opucsta a otra categoría abstracta la del narratario, o lcctor-oycnte abstracto.

2. Ninguna de estas tres posiciones confiere papel alguno al autor y, mucho menos, lo opone al lector. Ciertamente esto ocurre por diferentes motivos: en Kayser, porque al narrador y al autor les corresponde el mismo papel: el de creadores de universos, pero es el narrador, espíritu de la creación, el que realmente lo desempeña; en Genette y Greimas, porque sólo están interesados en el texto verbal y no les interesa su exterior; y en Tamir, porque su «funcionalismo» le impide plantearse cuestiones «oṇtológicas». Y

3. Las tres posiciones representan concepciones rigurosamente acrónicas del problema. Suponen que la proyección del autor en el Quijote tiene que se la misma que la del Ulysses. Kayser combatía a los que postulaban la desaparición del narrador elevando a categoría esencial y acrónica un problema histórico. Genette y Tamir no parecen conscientes de la existencia de la historia, subyugados por la falacia de los universales del relato.

Una reconsideración de estas posiciones desde un punto de vista enunciativo nos

de los niños, primer estadio del discurso interior. Cuando el niño empieza a hablar articula una sola palabra, pero le adjudica un significado global. El aprendizaje consiste en ir acumulando palabras a las que se les adjudica significados cada vez más parciales; procede así el niño de lo particular a lo general en el nivel acústico y de lo general a lo particular en el nivel semántico.

9.- Nos referimos a Brioschi-Di Girolamo (1988: 209). Más adelante, en ese mismo manual se asegura que quien organiza «el material, siguiendo una estrategia más o menos consciente», es el «autor implícito» (p. 211). 
lleva a las siguientes conclusiones. En primer lugar, resulta vital la recuperación del papel del autor-creador. No hay enunciado sin enunciador. $Y$, si no son pocos los teóricos que han renunciado a señalar la responsabilidad del autor-creador, es porque sus concepciones de la obra literaria se reducen al material verbal - en el caso de los estructuralistas - y, desde un punto de vista estético, al simple objeto de consumo - lo que les hace olvidar la relevancia comunicativa que tiene el arte, verbal y no verbal, en la sociedad-. Desde este punto de vista es posible imaginar categorías mecánicas sin responsabilidad artística ni enunciativa.

En segundo lugar, hemos de tener en cuenta que ese autor-creador no permanece enteramente exterior a su obra, sino que representa el mundo, bien desde el personajenarrador, bien desde un autor-narrador interpuesto - del tipo del Cide Hamete Benengeli cervantino-, bien mediante su propia voz más o menos debilitada - fuerte en el tipo omnisciente que domina la novela moderna hasta principios del siglo XX, débil en la novela característica de este siglo-. Esta triple proyección del autor-creador en la obra narrativa supone importantes problemas enunciativos, que sólo pueden ser abordados desde una perspectiva histórica. Podemos enumerar estos problemas enunciativos del siguiente modo:

1. En el caso en que el autor se sirve de un narrador-personaje - que además es el héroe- pueden suceder dos cosas: primero, que ese personaje represente el punto de vista ideológico del autor o que represente un punto de vista contrario al del autor; $y$, segundo, que exista una disonancia cognitiva entre el presente de ese personaje narrador y su pasado, o que exista una consonancia entre ambas perspectivas cognitivas - más acertado resultaría decir que se da un solo plano cognitivo, el del tiempo narrado-. Los problemas de consonancia y disonancia han sido definidos por D. Cohn (1978). Un caso distinto lo representa el narrador-testigo: la narración puesta en la boca de un personaje que no es el héroe, técnica narrativa útil para la presentación de sucesos extraordinarios.

2. En los casos de autor interpuesto - Cide Hamete, etc. - resulta inevitable la aparición de un autor implícito. Se trata de una representación de la voz del autor característica de la novela más primitiva y que se mantiene hasta principios del siglo XX.

3. En los casos en que el autor narra con su propia voz puede suceder que esa voz se mantenga, aunque incorpórea, relativamente personificada, hablando en no pocas ocasiones en una primera persona que expresa su sujeto enunciativo y su sujeto cognitivo - que suele denominarse omnisciente-. Pero en el siglo XX la despersonalización de esa voz - -eso que se llama desaparición del narrador - da lugar a la pérdida de las señales discursivas de ese sujeto enunciador y a que las señales discursivas del sujeto cognitivo, que llevaba aparejado la voz del autor, se difuminen hasta el punto de pasar a servir a otros sujetos cognitivos - los personajes - o al menos a situarse a su misma altura. Este fenómeno es el que D. Cohn denomina figural narration, frente a la authorial narration de la novela anterior al siglo XX. Una cierta recuperación de la voz del autor se registra en novelas que la tradición crítica llama subjetivistas - La Colmena. Tiempo de silencio, etc.-, pero el estatuto de esta voz en este tipo de novelas está mucho más próximo al del personaje - es una voz entre otras - que al del viejo autor omnisciente.

\section{La voz dual}

Sin embargo, la manifestación más nítida de la existencia de ambos sujetos, enunciador y cognitivo, habremos de hallarla en el nivel del enunciado narrativo moderno. En los 


\section{LUIS BELTRÁN ALMERÍA}

enunciados narrativos el divorcio entre enunciador y observador ha adquirido carta de naturaleza en el dominio de la voz dual (en estudios de carácter lingǘstico se suele caracterizar la voz dual como discurso - o estilo-indirecto libre). En el dominio de la voz dual, a pesar de las múltiples fórmulas compositivas que puede adoptar, encontraremos el divorcio entre un sujeto entnciador, que será un personaje, y un sujeto cognitivo, que corresponde al autor-narrador en la narrativa impersonal - la narrativa en tercera persona- o al personaje narrador en la narrativa personal - la narrativa en primera persona-. $Y$, aunque en este segundo caso se trata de dos entes de fieción, dos personajes, son siempre personajes distintos, que desempeñan dos papeles opuestos: uno, el narrador, es el que relata y ve la historia y el otro, el interlocutor, es el que habla ${ }^{10}$. Esta concepción de la voz dual se opone a la de la larga nómina de lingüistas que han negado la posibilidad de un doble sujeto para un único enunciado - el caso más reciente es el Ann Banfield-, al tiempo que explica cómo llega a ser compatible la existencia de un doble sujeto para un mismo enunciado (más allá de las frases-eco, señaladas por Banfield 1982: 123-8).

Analizaremos, a-continuación, el relato que hace Elías Canetti en La antorcha al oído (Die Fackel im Ohr) de la intervención de su madre, en diálogo con él, acerca de dos mujeres - Veza y María-, que atraen a Elías.

Se hallaba tan poscída por mi relato que, sin ningún reparo, otorgó su preferencia a una de las dos mujeres. Yo no había decidido aún cuál prefería, pero ella hizo valer toda su autoridad en favor de María. Siempre es mejor, me dijo, pensar en alguien que esté lejos. La proximidad suele generar fricciones, todo se trivializa, y el violín también puede aportar un elemento falso a la relación. Después de todo, uno ama a un ser humano y no a su instrumento, si no, podría contentarse simplemente con sus conciertos. Y no fuera yo a creer, añadió, que ella quería conocer a María. No descartaba la posibilidad de que siguiera con ella hasta terminar mis estudios, es decir dos años más, justamente porque la chica vivía en Salzburgo y no en Viena. Claro que tenía curiosidad por conocerla, añadió: yo era un exagerado y a lo mejor ella no la encontraba tan bonita. Pero conocer a mi madre le daría a sus propios ojos una importancia que no le correspondía. Eso sí, nada de atarse:

10.- También puede considerarse en alguna medida voz dual el caso de lo que Cohn llama figural narration - la narración en tercera persona desde el punto de vista del personaje-. En este tipo de textos se produce una disolución del discurso del autor en beneficio del discurso del personaje. Este fenómeno narrativo adquiere unas formas discursivas particulares en las traducciones hispanas de los novelistas anglosajones que lo practican, como es el caso de Virginia Wolf. Veamos el curioso efecto del ejemplo siguiente:

Ahora el día se nublaba.

Volvió el sol, deslumbrante (El cuarto de Jacob, 31).

En la primera frase ahora y el imperfecto indican claramente que estamos en presencia de una voz dual. Pero la segunda frase el traductor no la ha entendido así y ha utilizado un indefinido que borra las señas de la dualidad de la frase original. Podemos decir que en la traducción española queda algo del discurso del personaje: su cognición; pero su deixis, sus marcas verbales han sido borradas, cosa que no sucede en el original. Aunque la legitimidad de esta traducción sea objetable, no lo es la legitimidad de la narración que resulta en castellano y sus inesperados resultados lingüísticos. 


\section{LA ENUNCIACIÓN NARRATIVA: EL NARRADOR Y LA VOZ DUAL}

tenía toda la vida por delante, hoy en día era una necedad atarse a los veintidós años (Canetti, La antorcha al oído, Madrid, Alianza-Muchnik, pp. 229-230)*11.

Preguntarse ante este texto quién habla es útil. A partir de Siempre es mejor... habla la madre de Elías, salvo en las frases parentéticas me dijo y añadió, que sirven para ayudar al lector a interpretar el texto como discurso ajeno relatado. Curiosamente, estas frases parentéticas han sido añadidas por el traductor: no aparecen en el original. Sin duda el traductor no confió en los signos enunciativos que caracterizan esta voz dual, a diferencia de Canetti, que no juzgó necesario señalar con parentéticas la dualidad. Y, en efecto, son innecesarias. Hay suficientes elementos semánticos, deícticos y sintácticos para que el lector pueda apreciar la presencia de discurso ajeno - el discurso de la madre- en el relato. En efecto, a partir de Siempre es mejor... la sintaxis se tiñe de giros orales (Claro que..., Eso si, etc.); la semántica adopta expresiones reveladoras del conflicto (yo era un exagerado); pero, sobre todo, podemos apreciar efectos deícticos inencontrables en textos que no contengan voz dual. La frase final es uno de los más nítidos casos de ahora en el pasado: hoy en día era una necedad atarse a los veintidós años; bien podría ser ésta una de las unspeakable sentences de Ann Banfield. Esta contradicción deíctica muestra el choque entre dos sujetos: aquel al que pertenece el discurso - el enunciador-, que dice hoy en día, y aquel que oye, observa y evalúa el discurso -el sujeto cognitivo-, que traslada el discurso a una forma narrada - era, ella, la madre-. También el uso del pronombre YO es significativo. El primer YO aparece subrayado -incluso en el original, ich-, frente a los demás, que no lo están. He aquí una huella gráfica de esta contradicción deíctica. El primer YO como el $m i$ de $m i$ relato son huellas del sujeto enunciador del narrador (Elías). En los demás YOs que siguen se expresa el interlocutor de la madre - es el TÚ del discurso materno- y son huellas del locutor que narra y del sujeto cognitivo que proyecta su propia visión retrospectiva sobre el discurso de su madre.

Quizá Genette y Ricoeur señalarían también que en este texto la respuesta a la pregunta quién habla es: la madre, y la respuesta a la pregunta quién ve u observa es Elías. Banfield señalaría el divorcio entre speaker y SELF _-entendiendo SELF como sujeto de conciencia, porque no hay en su teoría una delimitación entre sujeto de la enunciación y sujeto de conciencia-. Bajtín diría que es un enunciado que «sirve a dos señores», madre e hijo en este caso, expresión de la fusión de dos voces.

Pero estas diferencias con nuestro análisis no son lo que nos interesa ahora. Nos

11.- Naturalmente este ejemplo desautoriza la prohibición de Hamburger -compartida por $\mathrm{N}$. Tamir, entre otros - de que el discurso indirecto libre y las marcas de ficcionalidad aparezcan en narrativa personal.

* Von meiner Erzählung war sie so erfüllt, $\mathrm{da} \beta$ sie einer der beiden Frauen ohne Scheu den Vorzug gab. Es war gar nicht ausgemacht, welche ich lieber hatte, aber sie warf ihr volles Gewicht in die Waagschalc für Maria. Es sei immer besser, an jemand in der Ferne zu denken. In der Nähc reibc man sich aneinander wund, alles werde schal, auch bringe die Geige etwas Falsches in die Beziehung hinein. Man liebe schilie $\beta$ lich einem Menschen und nicht sein Instrument, sonst könnte man sich gelich mit seinen Konzerten begnügen. Doch solle ich nicht glauben, da $\beta$ sie Maria kennenlernen wolle. Sie halte es für möglich, da $\beta$ ich bis zum Ende meines Studiums, also noch zwei Jahre an ihr festhalten würde, eben weil sie in Salzburg sei und nicht in Wien. Neugierig sei sie schon auf sie, gewi $\beta$, ich sei ein Übertreiber und vielleicht fände sie sie gar nicht so schön wie ich. Aber eine Bekanntschaft mit der Mutter würde ihr in ihren eigenen Augen ein Gewicht geben, das ihr nicht zukomme. Nur nicht sich binden, das Leben stïnde offen vor mir, ein Narr, wer sich heutzutage mit 22 binde (Die Fackel im Ohr, pp. 216-217). 


\section{LUIS BELTRÁN ALMERÍA}

interesa más volver al hilo central de nuestra exposición: el concepto de sujeto de la enunciación. Podemos ver ahora lo inapropiado de una concepción del enunciador como puente entre sistema y discurso - la de Benveniste y Greimas-. Esta categoría mecánica, el puente entre sistema y discurso, no tiene lugar en el texto - como se ha encargado de subrayar Greimas a propósito de lo que él llama la «enunciación enunciada»-y no puede dar cuenta de los fenómenos o huellas que deja la enunciación en el enunciado y que dan lugar a los indicios de dualidad que hemos señalado más arriba. En otras palabras, la categoría benvenisteana de sujeto de la enunciación responde a las necesidades de coherencia de una teoría escindida en dos dominios: el dominio del sistema y el dominio del discurso. $Y$, por tanto, deja de responder a los fenómenos discursivos en los que se encuentra directamente implicada.

Tampoco la versión hamburgeriana del sujeto de la enunciación resulta muy útil aplicada a estos casos de dualismo. Hay que decir que la propia Hamburger advirtió que el enunciador era distinto del sujeto de conciencia. Y también hemos de tener en cuenta el problema que presenta la teoría hamburgeriana con la narrativa en primera persona, cuyo carácter híbrido entre la ficción y la no ficción pone de manifiesto. Con todo, lo fundamental de la concepción del sujeto de la enunciación en Käte Hamburger estriba en el carácter lógico de su oposición sujeto/objeto. Este carácter lógico dificulta la distinción entre enunciador y sujeto cognitivo, que ni aparece clara en Hamburger, ni en Banfield, que ni siquiera se la plantea. Afrontar el enunciado como objeto lógico debe imponer importantes restricciones a la percepción íntegra de los fenómenos que en él convergen, sobre todo cuando esa lógica es formal y no dialéctica.

Frente a estas concepciones formalizadas de la enunciación como mediación, hemos situado una concepción de la enunciación como dialéctica de la producción del discurso. En esta concepción no hay mediación entre dos ámbitos y dos objetos, sino un solo ámbito: el del lenguaje-discurso y, por tanto, un solo objeto, el discurso-enunciado. Las categorías mecánicas, producto de una constelación de oposiciones binarias, deben ser sustituidas por categorías dialécticas que respondan a elementos materiales concretos de la producción del discurso. A través de la descripción de la dialéctica de la enunciación, no percibimos una lista de categorías positivas, sino una vía de acercamiento a la naturaleza humana: su dimensión lingüística, esto es, social.

\section{Referencias Bibliográficas}

B. ITÍN, M. M.

1975 Voprosy literatury i èstetiki. Moscú, Xudozestvennaja literature. Traducción inglesa The dialogic imagination (four essays), Austin, University of Texas Press, 1981.

1979 Estetika slovesnogo tvorchestva, Moscú. Traducción española Estética de la creación verbal, Méjico, Siglo XXI eds., 1982.

BANFIELD, A.

1982 Unspeakable Sentences, Boston, Routledge \& Kegan Paul.

BENVENISTE, É.

1966 Problemes de linguistique générale. París, Gallimard.

1974 Problemes de linguistique générale II. París, Gallimard.

BERRENDONNER, A.

1982 Elements de Pragmatique linguistique. París, Minuit. Traducción española Elementos de Pragmática lingüística. Buenos Aires, Gedisa, 1987. 


\section{LA ENUNCIACIÓN NARRATIVA: EL NARRADOR Y LA VOZ DUAL}

BRIOSCHI, F. - DI GIROLAMO, C.

1988 Introducción al estudio de la literatura. Barcelona, Ariel.

COHN, D.

1978 Transparent Minds. Princeton, Princeton U. P.

DUCROT, $\mathrm{O}$.

1980 Les mots du discours. París, Minuit.

1984 Le dire et le dit. París, Minuit.

FREGE, G.

1892 «Über Sinn und Bedeutung», Zeitschrift fïr Philosophie und philosophische Kritik, 100, pp. 25-50, Traducción española «Sobre referencia y sentido» en Estudios sobre semántica, Barcelona, Ariel, 1984.

GENETTE, G.

1972 Figures III. París, Seuil.

1983 Nouveau discours du récit. París, Seuil.

GREIMAS, A. J. - COURTÉS, J.

1979 Sémiotique. Dictionnaire raisonné de la théorie du langage. París, Hachette. Citado por la traducción española Semiótica. Diccionario razonado de teoría del lenguaje. Madrid, Gredos, 1982.

HAMBURGER, K.

1957 Die Logik der Dichtung. Stuttgart, E. Klett y J. G. Cotta/dtv, 1987.

JAKOBSON, R.

1970 Essais de linguistique générale. Trad. esp. Ensayos de lingüística general. Barcelona, Seix-Barral, 1975.

KAYSER, W.

1958 «Wer erzählt den Roman?» en Die Vortragsreise, Berne, Francke Verlag, pp. 82101; tr. fr. «Qui raconte le roman?» en Poétique du récit. París, Seuil, 1977.

LÁZARO CARRETER, F.

1987 «La lógica de la literatura» en Saber leer (Revista crítica de libros), n.․ 4, pp. 10-11.

RICOEUR, P.

1984 Temps et récit. París, Seuil; traducción española Tiempo y narración II, Madrid, Cristiandad, 1987.

1986. Du texte à l'action. Essais d'herméneutique Ll, París, Seuil.

ROSS, J.

1970 «On Declarative Sentences» en R. A. Jacobs \& P. S. Rosenbaum, eds. Readings in English Transformational Grammar. Massachusetts, Ginn, pp. 222-272.

STANZEL, F. K.

1979 Theorie des Erzahlens, UTB Vandenhoek, Göttingen, 1985, 3. a ed.

TAMIR-GHEZ, N.

1976 «Personal Narrative and Its Linguistic Foundation», Poetics and Theory of Literature, vol. 1, pp. 403-429.

VOLOSHINOV, V.

1929 Marksizm i filosofiia iazika, Leningrado. Traducción española El signo ideológico y la filosofía del lenguaje. Buenos Aires, Nueva Visión, 1976.

VYGOTSKI, L. S.

1934 Pensamiento y lenguaje. Buenos Aires, Pléyade, 1973. 